\title{
WORK-RELATED UPPER LIMB MUSCULOSKELETAL DISORDERS (WRULMSDS) RISK ASSESSMENT: DIFFERENT TOOLS, DIFFERENT RESULTS! .WHAT ARE WE MEASURING?
}

\author{
EVALUACIÓN DE RIESGO DE ETRSME TMOLCE: \\ DIVERSAS HERRAMIENTAS, DIVERSOS RESULTADOS! \\ QUÉ ESTAMOS MIDIENDO?
}

\author{
FLORENTINO SERRANHEIRA*, ANTÓNIO DE SOUSA UVA**
}

(*) Florentino Serranheira, MSc, PhD - Ergonomist, Assistant Professor, CIESP, National School of Public Health - New University of Lisbon (Environmental and Occupational Health Department).

(**) António de Sousa Uva, MD, PhD - Medical Doctor and specialist in Occupational Health Medicine, Full Professor, CIESP, National School of Public Health - New University of Lisbon

(Head of the Environmental and Occupational Health Department).

\section{RESUMEN}

Varios métodos pueden ser usados para la evaluación del riesgo de enfermedades profesionales relacionadas con el sistema musculoesquelético o trastornos musculoesqueleticos del cuello y de las extremidades superiores (TMOLCE).

Comparamos diferentes métodos y sus resultados en el mismo lugar de trabajo que intenta contribuir para una evaluación de riesgo más exacta de TMOLCE basado en la identificación del los factores (profesionales) de riesgo. Este estudio fue desarrollado en una planta automotora e incluyó todos los sitios de trabajo $(\mathrm{n}=366)$ estudiados previamente con la lista de comprobación de OCRA. La metodología incluyó la reutilización de la lista de comprobación de OCRA en todos los sitios de trabajo con las cuentas OCRA $\geq 16,5 \quad(n=152)$. En los lugares de trabajo de alto riesgo $(\mathrm{n}=71)$ también aplicamos tres otros métodos de "evaluación del riesgo": (a) Rapid Upper Limbs Assessment - RULA; (b) Strain Index - SI; (c) Hand Activity Level - HAL. La actividad del trabajo también ha sido grabada y los factores de riesgo principales analizados. El análisis se centra en el miembro superior derecho. Los resultados fueron diferentes en función del método usado; notablemente, demuestran el desacuerdo en la clasificación de los sitios de trabajo de riesgo elevado. Así, (a) OCRA tiene una correlación moderada $(\mathrm{p}<0,001)$ con $\mathrm{SI}\left(\mathrm{r}_{\mathrm{Sp}}=0,52\right)$ y con $(\mathrm{b}) \mathrm{HAL}$ $\left(\mathrm{r}_{\mathrm{Sp}}=0,42\right)$; (c) HAL tiene una correlación fuerte con $\mathrm{SI}\left(\mathrm{r}_{\mathrm{Sp}}=0,77\right)$ y (d) las cuentas de RULA no se correlacionan con los otros métodos.

OCRA, el SI, RULA y HAL demuestran resultados de riesgo distinto que confirman la necesidad de un criterio de selección. El saber de los factores de riesgo presentes en cada permiso del sitio de trabajo permite la selección del método más exacto. Los resultados de la evaluación de riesgo de diverso WRULMSD influenciarán la gestión del riesgo. Solo un conocimiento riguroso del sitio de trabajo y del criterio consecuente de selección del método permitirá que el proceso sea más eficaz.

\section{PALABRAS CLAVES}

Trastornos musculoesqueleticos de origen laboral del cuello y de las extremidades superiores (TMOLCE); Evaluación del riesgo ocupacional; métodos observacionales de evaluación de riesgo de TMOLCE.

\section{ABSTRACT}

Several methods may be used for Work-Related Upper Limbs Musculoskeletal Disorders (WRULMSDs) risk assessment. We compare different methods and their results at the same workplace trying to increase a more accurate WRULMSDs risk assessment based at the hazard identification.

This study took place at an automotive plant and included all the workstations $(n=366)$ which has been previously studied with OCRA checklist. The methodology included the re-application of OCRA checklist at all workstations with scores OCRA $\geq 16,5$ $(n=152)$. At workplaces with high risk $(n=71)$ we also applied three other methods of "risk evaluation": (a) Rapid Upper Limb Assessment; (b) Strain Index; and (c) Hand Activity Level. Work activity has been also videotaped and the main risk factors were analyzed. The analysis is focused on the right upper limb.

Outcomes were different with the use of each method, notably, they show disagreement in the categorization of high-risk workstations. So, (a) OCRA has a moderate correlation ( $\mathrm{p}<0,001)$ with SI $\left(\mathrm{r}_{\mathrm{Sp}}=0,52\right)$ and with (b) HAL $\left(\mathrm{r}_{\mathrm{Sp}}=0,42\right)$; (c) HAL has a strong correlation with SI ( $\left.\mathrm{r}_{\mathrm{Sp}}=0,77\right)$ and (d) RULA scores are not correlated with the others methods.

OCRA, SI, RULA and HAL show evidence of distinct risk results that confirm the need of a selection criterion. The knowing of witch risk factors are presents at each workstation permit the selection of the most accurate method. Different WRULMSD's risk assessment results will influence risk management and just with a workstation rigorous knowledge and the consequent method selection criterion, the process may be more effective.

\section{KEY WORDS}

Work-related upper limbs; musculoskeletal disorders (WRULMSDs); Occupational risk assessment; WRULMSDs observational risk assessment. 


\section{Introduction}

Work-Related Upper Limb Musculoskeletal Disorders (WRULMDs) are common disorders in the industrial world, particularly when workers are exposed to occupational "risk factors" that include physical factors, with awkward work postures, force exertion, e.g. lifting, pulling or pushing; high movement's repetitiveness; and exposure to vibrations (1-7).

WRULMSDs risk management must be based on an accurate risk assessment. Several methods may be used, most of which are based on practical exposure assessment tools frequently selected and used by non experts. The evaluation of the potential harm (risk) may therefore lead to likely invalid results and inappropriate control measures if not used accurately. Management programs require the definition of a correct risk rating.

Risk assessment methods are made for enable the identification of "risk factors" and to evaluate the WRULMSDs risk which may be faulty by a lot of causes once (i) they are conditioned by the characteristics of their qualitative evaluations; (ii) they only allow the evaluation of the pre-specified aspects; (iii) they depend on the experience and knowledge of people using them. On the other hand, those methods selection are usually related with the familiarity that the user presents with each one of them, what will influence all the risk assessment and management processes (8). Causation of WRULMSDs is always multifactorial in nature, and work must be studied taking into consideration this causal model.

Risk assessment tools vary from (i) simple checklists to identify symptoms and its relationships with work activity or professional title (self-assessment questionnaires); (ii) filters that are used to WRULMSD's risk factors identification as the RSIHSE; (9) (iii) observational methods as the Occupational Repetitive Actions - Cheklist (OCRA) (10), the Rapid Upper Limb Assessment (RULA) (11), the Strain Index (SI) (12) and the Hand Activity Level (HAL) (13) applied at workplaces in real time; (iv) or using video records; and (v) instrumentation methods as EMG or electrogoniometry.

In the context of musculoskeletal disorders
(MSD) risk assessment methods as the previously mentioned, if well conceived and structured and used by specialists or people with training in ergonomics, should be seen as an effective risk evaluation process in an integrated management approach (14).

\section{MATERIAL AND METHODS}

\section{Workstations selection}

This study took place at an automotive plant and included all the existing workstations $(n=366)$ previously studied with OCRA checklist - the more simple tool (Ochippinti, 1998). The methodology was applied through different stages beginning with the reapplication of OCRA checklist at all workstations with high scores $(n=152)$.

\section{Risk assessment methods}

OCRA checklist was applied by two experts (ergonomists) with previously methods experience and the scores are obtained by consensus. The analysis focused only on the right upper limb. At the workplaces presenting levels of moderate/high risk $(n=71)$ of WRULMSDs (score OCRA $\geq 16,5)$ the risk was also assessed by three other methods of "risk evaluation" at the plant following method authors procedure application and considered risk factors:

- OCRA - Occupational Repetitive Actions (checklist) (Ochippinti, 1998):

- Type of work interruption (with pauses or other visual control tasks) - Recovery;

- Arm activity and working frequency with which the cycles are performed - Frequency;

- Presence of working activities involving the repeated use of force in the hands-arms Force;

- Presence of awkward postures in the upper limbs during a repetitive task - Posture;

- Presence of additional risk factors - Additional risk factors.

- RULA - Rapid Upper Limb Assessment (McAtamney \& Corlett, 1993);

- Arm and Wrist Analysis: 
Upper Arm Position

LowerArm Position

Wrist Position

Wrist Twist

Muscle Use

Force/load

- Neck, Trunk and Leg Analysis:

Neck Position

Trunk Position

Legs

- SI - Strain Index (Moore \& Garg, 1995):

- Intensity of exertion

- Duration of exertion (\% of cycle)

- Efforts/minute

- Hand/wrist posture

- Speed of work

- Duration per day (hours)

- HAL - Hand Activity Level (Lakto et al., 1997):

- Hand Activity Level Rating

- Estimation of Normalized Peak Force for Hand Forces

\section{Data Analysis}

Each risk factor contribution to the final score (those presented at the method) as been analyzed at the different methods trying to find the method major (in)balance and achieving a possible indication for selection criteria to the most accurate method for each workplace based on the main risk factor exposure. Final scores are also compared and those analyses are done by means of Spearman rankorder correlation coefficients $\left(\mathrm{r}_{\mathrm{Sp}}\right)$.

Excel $^{\odot}$ and Statistical Package for Social Sciences $\left(\mathrm{SPSS}^{\odot}\right.$ vs14 for Windows) software were used for data analysis.

\section{RESULTS}

\section{Occupational Repetitive Actions (OCRA checklist)}

The OCRA scores distribution obtained reveals the existence of areas with more workstations showing risks from moderate to high, whilst others, on the contrary, had a majority of workstations with low risk. Such results might be related to the different work postures, some of them with the arms above the head or with the need for repetitiveness, hand force and vibrations exposure.

The distribution of risk levels (Table I) shows 37 workstations as having a moderate risk $(O C R A \geq 16,5)$ and 34 classified as high risk $(\mathrm{OCRA} \geq 19)$.

\begin{tabular}{|cc|c|c|}
\hline & & Frequency & Percent \\
\hline OCRA & 16,5 & 13 & 18,3 \\
scores & 17,0 & 11 & 15,5 \\
& 17,5 & 8 & 11,3 \\
& 18,0 & 4 & 5,6 \\
18,5 & 1 & 1,4 \\
19,0 & 11 & 15,5 \\
19,5 & 4 & 5,6 \\
20,0 & 9 & 12,7 \\
20,5 & 3 & 4,2 \\
21,5 & 2 & 2,8 \\
23,0 & 1 & 1,4 \\
24,0 & 2 & 2,8 \\
26,0 & 2 & 2,8 \\
Total & 71 & 100,0 \\
\hline
\end{tabular}

Table I: OCRA Scores

When applying the OCRA method, the first element to be taken into account is the risk factor "recovery time period". This reveals identical results for all workstations analyzed which can be explained by a set of similar patterns of working schedule for all the workers in the production line or the set of sequential operations established (level 4 there are two coffee-breaks and a lunch break).

Results show 16 workstations with moderate risk levels for the risk factor "frequency" (level 4 - rapid and regular motions - near 40 technical actions by 
minute with occasional and irregular pauses). It should be noted that there are 11 workstations with level 5, 10 workstations with level 6 and 3 workstations with level 8 . In all those workstations the frequency of technical actions shows the presence of rapid (or very rapid) movements of the upper limbs performed during work activity.

Force results were obtained from partial estimation where evaluations of moderate and high force were represented. The result of risk factor "OCRA force" is significantly related $\left(\mathrm{r}_{\mathrm{Sp}}=0,706 ; p<0,01\right)$ with the level of high force and in a less evident degree with moderate force $\left(\mathrm{r}_{\mathrm{Sp}}=0,421 ; p<0,01\right)$.

For the upper posture, results show the inexistence of maximum scores (risk=8). 15 workstations have been classified with reduced risk. Elbow posture presents scores ranging from 0 to 8 and at the analyzed workstations those are low level of pressure. There are 30 workstations with very low risk level for the elbow.

Wrist OCRA scores revealed values between 2 $(\mathrm{n}=1)$ and $5(\mathrm{n}=26)$, in a scale ranging from 0 to 6 , that demonstrate the contribution of this risk factor to the overall level of postural risk.

Concerning the records for the posture of the hand and fingers, which mean the way in which workers hold or grip objects tools or items, the mode was $4(n=27)$ and 15 workstations were scored 5 and one 6 (extreme postures). It should be noted that the scale ranges from 0 to 8 .

Working gestures weren't identical or repeated around $2 / 3$ of the cycle time for none of the workstations. As a matter of fact, none of the workstations have only one task or work cycles below 15 seconds.

Results obtained for the "posture" of each anatomical segment, where should be noted the "negative" results for the wrist and the hand, allow us to obtain the score OCRA for posture. The analysis of the association between the different factors contributing for the result of posture show a significant $(p<0,01)$ correlation with posture score $\left(\mathrm{r}_{\mathrm{Sp}}=0,456\right)$.
Concerning additional risk factors, the percentages of occupational time of activity at workstations between $50 \%$ and $75 \%(n=36)$ and among $75 \%$ and $90 \%(n=31)$ for risk factors of group I should be noted. For group II factors the positive result is shown by the absence of any of those factors $(n=30)$ and the negative one by the frequent use of the hands as a hammer $(\mathrm{n}=31)$.

The OCRA final score displays a moderate correlation $\left(\mathrm{r}_{\mathrm{Sp}}=0,620 ; \mathrm{p}<0,01\right)$ with risk factors such as the "wrist posture" and a minor correlation with global posture $\left(\mathrm{r}_{\mathrm{Sp}}=0,263 ; \mathrm{p}<0,01\right)$. Evidence goes to risk factors such as the strong "force exertion" $\left(\mathrm{r}_{\mathrm{Sp}}=0,421 ; \mathrm{p}<0,01\right)$ and the "overall force" $\left(\mathrm{r}_{\mathrm{Sp}}=0,398 ; \mathrm{p}<0,01\right)$. "Frequency" shows a minor correlation with OCRA score $\left(\mathrm{r}_{\mathrm{Sp}}=0,340 ; \mathrm{p}<0,01\right)$. Additional risk factors have correlations nearing zero (I: $\mathrm{r}_{\mathrm{Sp}}=0,07 ; \mathrm{p}=0,563$ and II: $\mathrm{r}_{\mathrm{Sp}}=0,288$; $\mathrm{p}=0,15)$.

\section{Strain Index (SI)}

Strain Index (SI), a method to analyze jobs with risk of distal upper extremity disorders, was applied in the same 71 workstations with moderate or high OCRA scores (OCRA $\geq 16,5)$. Results allow us to identify 21 workstations with minor risk, 9 workstations with unknown risk, and 41 workstations with moderate and high risk levels, following the interpretation of the authors about the risk results (Table II).

Final score SI results from a multiplication of six different "risk factors":

- "intensity of exertion", i.e the force required for a single task;

- "duration of exertion" i.e the proportion of the exertion cycle;

- "efforts per minute" i.e. the frequency of exertion;

- "hand/wrist posture" rated subjectively;

- "speed of work" also rated subjectively;

- and "duration of task per day" based on the observer's perception. 


\begin{tabular}{|ll|c|c|}
\hline & & Frequency & Percent \\
\hline SI &, 4 & 1 & 1,4 \\
Scores &, 5 & 3 & 4,2 \\
&, 6 & 2 & 2,8 \\
&, 8 & 2 & 2,8 \\
& 1,1 & 3 & 4,2 \\
& 1,5 & 1 & 1,4 \\
& 2,3 & 5 & 7,0 \\
& 3,0 & 4 & 5,6 \\
3,8 & 1 & 1,4 \\
4,0 & 1 & 1,4 \\
4,5 & 7 & 9,9 \\
5,6 & 1 & 1,4 \\
6,0 & 8 & 11,3 \\
6,8 & 1 & 1,4 \\
8,0 & 1 & 1,4 \\
9,0 & 3 & 4,2 \\
10,1 & 2 & 2,8 \\
10,5 & 2 & 2,8 \\
11,3 & 1 & 1,4 \\
12,0 & 2 & 2,8 \\
13,5 & 6 & 8,5 \\
18,0 & 3 & 4,2 \\
22,5 & 5 & 7,0 \\
24,0 & 4 & 5,6 \\
48,0 & 2 & 2,8 \\
Total & 71 & 100,0 \\
\hline
\end{tabular}

Table II: SI Scores

The product, with multipliers, of the six variables produces the Strain Index score that is compared to a gradient that identifies the level of task's risk.

For 23 workstations there was a moderate force application and for 9 workstations the force was almost absent. As opposed to these results, 12 workstations scored force as very intense (level 6 of CR10 scale).

"Intensity of exertion" shows a strong correlation $\left(\mathrm{r}_{\mathrm{Sp}}=0,717 ; \mathrm{p}=0,01\right)$ with SI score and together with "duration of exertion" and "efforts per minute" they justify above $94 \%$ of SI score variation.

"Duration of exertion" allows the identification of force exertions below $30 \%$ of the cycle time $(n=56)$ indicating a possibility to recover from effort. Nevertheless, 15 workstations were identified as having levels of duration of exertion above $30 \%$ of cycle time.

"Efforts per minute" are related with frequency. There are 39 workstations with 8 or fewer exertions per minute and 2 workstations with more than 20 exertions per minute.
The evaluation of "hand/wrist posture" allows the identification of comfort posture deviations with a significant number of workstations with results revealing risk $(\mathrm{n}=45)$. Only 7 workstations have comfortable "hand/wrist postures" and 19 have a strong deviation from neutral posture.

Posture shows a low correlation with final SI score $\left(r_{\mathrm{Sp}}=0,246 ; \mathrm{p}=0,038\right)$. Speed of work is regular at 64 workstations and only in the others 7 workstations intense rhythms were observed. Duration of task per day is the same for all workstations - level 1 at SI.

The contribution of each risk factor to the SI final score is unequal. Force and effort seem to be the largest and most significant $(\mathrm{p}<0,01)$ contribution (efforts per minute $\mathrm{r}_{\mathrm{Sp}}=0,893$; duration of exertion $\mathrm{r}_{\mathrm{Sp}}=0,788$; intensity of exertion $\mathrm{r}_{\mathrm{Sp}}=0,717$ ) which emphasizes its relevance to the final SI score.

\section{Rapid Upper Limb Assessment (RULA)}

Also RULA was applied in the same workstations. RULA is an observational and integrated method for assessment of WRULMSD risk with evidence for working postures. It integrates risk factors such as posture, repetition and force.

Results show, for longest held posture, 5 workstations with low risk (levels 1 or 2), 40 also with low results (levels 3 and 4), 19 workstations requiring a more detailed investigation and rapid changes (level 5 and 6) and finally the other 7 workstations where results lead to an investigation and urgent changes (level 7) (Table III).

\begin{tabular}{|cc|c|c|}
\hline & & Frequency & Percent \\
\hline RULA & 1,0 & 2 & 2,8 \\
Scores & 2,0 & 3 & 4,2 \\
& 3,0 & 33 & 46,5 \\
& 4,0 & 7 & 9,9 \\
& 5,0 & 14 & 19,7 \\
& 6,0 & 5 & 7,0 \\
& 7,0 & 7 & 9,9 \\
& Total & 71 & 100,0 \\
\hline
\end{tabular}

Table III: RULA Scores 
The first step is to identify arm postures. Scores above $4(n=15)$ are identified and half of then $(n=8)$ are workstations with prevalent postures of arm above the shoulder. There are also 13 workstations with frequent arm abduction. Arm posture has a moderate correlation $\left(\mathrm{r}_{\mathrm{Sp}}=0,549 ; \mathrm{p}<0,001\right)$ with RULA scores.

Upper arm postures show risk levels above 4 $(n=15)$ that, half of them $(n=8)$, are related with work performed above shoulder level. Upper arm posture is moderately correlated $\left(\mathrm{r}_{\mathrm{Sp}}=0,549\right.$; $\mathrm{p}<0,001)$ with RULA scores.

Extreme flexion of the arm was observed only at 2 workstations. Posture of the arm is mainly classified as low risk: RULA level $2(n=34)$ mostly with arm at extension between 0 and $60^{\circ}(\mathrm{n}=32)$. Arm posture has a low correlation with RULA score $\left(r_{\mathrm{Sp}}=0,266 ; \mathrm{p}=0,025\right)$.

Wrist posture attain evidences scores $2(n=41)$ and among them there are 21 that outcome from wrist neutral (score 1) and deviation (score 1). There are also: (1) 18 workstations with score 3 and some composite by 3 score of moderate flexion $\left(0\right.$ to $\left.15^{\circ}\right)$ and wrist deviation; (2) 10 workstations with scores 3 result from wrist extension $\left(0\right.$ to $\left.15^{\circ}\right)$ and wrist deviation and (3) 5 workstations where the dominant postures are wrist extension (above $\left.15^{\circ}\right)(\mathrm{n}=3)$ and flexion (above $\left.-15^{\circ}\right)(\mathrm{n}=2)$. Wrist posture had low correlation with RULA score $\left(r_{S p}=0,299 ; p=0,011\right)$.

That kind of exposition to this risk factor was observed at only one workstation.

Intermediate postural results denote scores between 1 and 9 . Mostly they are between scores 3 and $4(\mathrm{n}=59)-$ moderate risk. Only 5 workstations had a score of 5 . RULA repetitiveness only identify 15 workstations with score 1.

There is no evidence of force exertion above 2 $\mathrm{Kg}$ or it is intermittent at 50 workstations. Only 3 workplaces indicate the use of the hand as a hammer.

Upper limbs RULA scores reveal lower upper limbs risk (minor then 4: $n=49$ ). There are 21 workstations with RULA upper limbs score 5 and 6 and just one workstation classified with score 7 .
Cervical score of 1 is predominant $(n=35)$. Only 13 workstations had score 4 (combination of cervical flexion and lateral rotation).

For Body the scores are mainly $1(n=51)$ and only at a few workstations $(n=3)$ there are classifications of level 3 (flexion above $20^{\circ}$ ).

Feet are well supported at the majority of situations $(n=68)$.

Postural scores of cervical, trunk and lower limbs are predominantly level $1(\mathrm{n}=27)$ and the others are equal or above $5(n=14)$.

According to RULA there are 40 workstations with scores 3 or 4 (moderate/low risk - investigate sooner) and 26 with high upper limbs risk (investigate and change immediately).

RULA scores are outcome from the combination of upper limbs, cervical, trunk and lower limbs results. Those denote moderate intermediate relations with global RULA scores (upper limbs posture $\mathrm{r}_{\mathrm{Sp}}=0,625 ; \mathrm{p}<0,01$ and arm $\left.\mathrm{r}_{\mathrm{Sp}}=0,549 ; \mathrm{p}<0,01\right)$. It is also possible to analyze those scores singly using upper limbs results, which indicates an ever greater relation with RULA score (upper limbs posture $\mathrm{r}_{\mathrm{Sp}}=0,792 ; \mathrm{p}<0,01$ and arm $\left.\mathrm{r}_{\mathrm{Sp}}=0,678 ; \mathrm{p}<0,01\right)$. Perhaps lower limbs score or trunk score poorly influence final RULA score at this kind of workstation.

\section{Hand Activity Level (HAL)}

Scores HAL obtained at the same workstations that OCRA were applied, indicate 35 workplaces with high WRULMSD risk (TLV $\geq 0,78$ ). We found workplaces that are at the activity limit (AL) $(n=19)$ and 17 workplaces were above that limit (Table IV).

At 21 workstations the manual activity is classified as slow steady motion with frequent brief pauses. There are also 21 workstations where work is performed with frequent motions and some pauses. At 29 workplaces the work is continuous and there are infrequent, uneven or no pauses at all.

Hand activity is at the opposite side to what was expected, that means that there is no relation to HAL score $\left(\mathrm{r}_{\mathrm{Sp}}=0,095\right)$. 


\begin{tabular}{|ll|c|c|}
\hline & & Frequency & Percent \\
\hline HAL &, 13 & 5 & 7,0 \\
Scores &, 17 & 1 & 1,4 \\
&, 25 & 2 & 2,8 \\
&, 33 & 1 & 1,4 \\
&, 40 & 2 & 2,8 \\
&, 50 & 6 & 8,5 \\
&, 60 & 6 & 8,5 \\
&, 67 & 9 & 12,7 \\
&, 75 & 4 & 5,6 \\
, 80 & 6 & 8,5 \\
, 83 & 3 & 4,2 \\
1,00 & 22 & 31,0 \\
1,17 & 2 & 2,8 \\
1,25 & 1 & 1,4 \\
1,67 & 1 & 1,4 \\
Total & 71 & 100,0 \\
\hline
\end{tabular}

Table IV: HAL Scores

Normalized peak force is obtained with alternative Moore \& Garg scale. There are 13 workstations with barely noticeable or relaxed effort, 42 workstations with moderate effort without facial expression and 16 workstations with substantial effort and changes to facial expression.

\section{Summary of results}

As expected there are divergent results with distinct methods for the same workstation (Table V). Differences between classifications at same workstation denotes a clear divergence with RULA and OCRA methods, including at their correlations $\left(r_{\mathrm{Sp}}=-0,126\right)$.

Globally, results were quite different with the use of each method, notably, the disagreement among the methods in the categorization of high-risk workstations, that is, for example the 31 workstations with high risk scores with SI only encloses 7 classified with RULA as high WRULMSDs risk and out of these only 3 are coincident.

\section{DISCUSSION}

Results obtained in previous studies (15) identified divergences of risk levels when applying different methods of WRULMSD integrated risk evaluation (RULA and SI), for the same workstations.

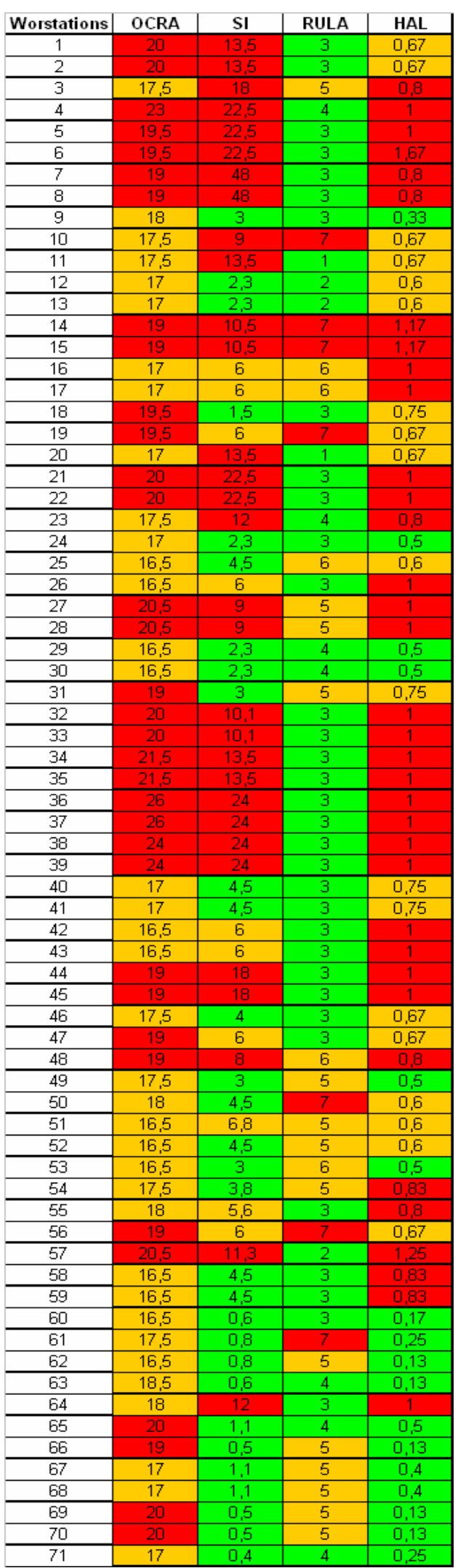

Table V: WRMSDs methods scores 
The option for workstations classified as risk moderate/high is based on the assumption that a real need for intervention exists and, in that sense, it was questioned the presence of "genuine" risk levels with the 4 methods used. A discrepancy was observed concerning the number of workstations classified as risk moderate/high when comparing the reference assessment with OCRA checklist and its reapplication, which is thought to be related, mainly, with increase cycle in the assembly line. This might mean that it is possible to reduce the WRULMSDs risk by decreasing the exposure to the main professional risk factors with the increase of the cycle time.

Applied methods (OCRA, RULA, SI and HAL) focus on the upper limbs WRULMSDs risk assessment and there still is insufficient evidence-based literature pointing towards the right application or other selection criteria for their application at the workstations. That leads us to other questions: (16)

- Is it possible to identify the correct method for each workstation?

- Is it possible to identify the risk factors and then select the method?

- Are risk filters (hazard identification checklists) the path to the selection of the right method selection?

Spielholz et al. (17) studied a cohort of 1.000 workers for three years and used RULA, SI and HAL, like in the present study. Preliminary results also point towards divergences in the risk levels. In average, Spielholz results present RULA with around $28 \%$ workstations with high risk levels, SI with $19,8 \%$ and HAL with approximately $19 \%$. It is possible to observe, like in the present study, similar global risk levels between the methods SI and HAL (43,6\% and $49,3 \%$, respectively), possibly due to identical risk factors weights and to the use of the same psychophysical scale (Borg's CR10) for the evaluation of the risk factor "use of force". Differences in classifications obtained from those methods in relation to the ones obtained with RULA were also identified. These differences can be related to distinct mechanisms of evaluation, i.e., for instance RULA mainly evaluates postural aspects in the performance of the work's activity.
According to the authors of the OCRA checklist (10), the risk factor "frequency of technical actions" or "repetitiveness" is critical in the development of WRULMSDs. In spite of that, the relation between that risk factor and the OCRA's score is low but significant $\left(\mathrm{r}_{\mathrm{Sp}}=0,340 ; \mathrm{p}=0,004\right)$. Assuming that the movements of the wrist, hand and fingers are at the "technical actions", only when they are more than 50 per minute will obtain scores of high level in the assessment method. This situation is not individualized by anatomical zone and, in extreme circumstances, a grip with a movement of the fingers requiring a movement of the hand and wrist will correspond to one single technical action when, in fact, three anatomical movements occurred. According to the results obtained in the current study this type of procedure can raise doubts regarding methods mainly based on the analysis of the prescribed work out coming from a method time measurement (MTM) analysis.

When analyzing the existing "extremes" between the methods used it can be verified that HAL method does not include any posture score while RULA details several possibilities of joint's movement, classifying these "negatively" according to the postural deviation from the neutral joint position.

Three out of the four used methods (OCRA, RULA and SI) provide different classification systems for the "posture" of the upper limb. The analysis of the records of the posture risk factor identifies OCRA as giving a substantial contribution for the wrist posture (31 workstations with level 4 - posture extreme more than half of the cycle time - and 26 with level 5) and for the hand/fingers (27 workstations with level 4 and 15 with level 5). RULA identifies classifications distant from the neutral position for the joint of the elbow with a predominance of the classification of level $2(n=34)$ - forearm flexed between $0^{0}$ and $60^{\circ}$; regarding the wrist joint, only the situations identified as extreme $(\mathrm{n}=18)$ were highlighted. Finally, the third method (SI) registers for the posture of the hand/wrist, 45 situations non neutral - value 1,5 - and only 19 with heighten deviations from neutrality - value 2,0.

The existence of "force exertions" in the workstations submitted to analysis is one of the main elements in WRULMSDs risk evaluation. HAL and SI 
give a major emphasis to that risk factor while RULA, in spite of taking into consideration strength with 4 levels of record, does not give it a similar weight.

Concerning the risk factor "force" it is observed that OCRA uses a classification system supported by the presence (or absence) of repetitiveness in the use of force. This criteria means that one single force exertion, in a cycle of work lasting for more than 2 minutes, may be undermined, even when the exertion is classified as high level. In this way, in the situations where repeated force was identified the classification is obtained cumulatively with the aid of two typologies: intense strength and moderate strength - which can coexist. It is the intense force $(\mathrm{n}=28)$ that contributed the most for the relation with the final OCRA score $\left(\mathrm{r}_{\mathrm{Sp}}=0,706 ; \mathrm{p}<0,01\right)$ and, overall the record of this risk factor shows high level of predictive validity, namely the sensitivity ( $88 \%$ ), the likelihood of false negatives $(12 \%)$, the performance of the test $(76 \%)$ and the intensity of the association $(\mathrm{OR}=10,1[3,06-33,49])$.

SI also highlights "force" in three of its six variables (effort's intensity, effort's duration and efforts per minute). The first element of the record - effort's intensity - is based on a modified Borg CR10 scale and it should be noted at this study that there are records of low and moderate force equal or below to level $3(n=23)$ or higher $(n=39)$. RULA presents different "force" scores once the importance to the application of force below $2 \mathrm{~kg}(\mathrm{n}=50)$ is substantial nevertheless the anatomical zone of force exertion (arm or fingers). Finally, HAL presents two standardized peak of force approach: the Borg CR10 scale and, as SI, a modification of this scale. The values worth to mention in this study correspond to levels of force equal $(n=20)$ or higher than $3(n=38)$.
In spite of the existence of several methods available in literature, we believe their selection should consider the "timing" of risk assessment and a first step based on "hazard identification", for instance, the Health and Safety Executive filter (13). This kind of approach will permit some hierarchical risk classification, fundamental for the next steps.

This results show these WRULMSDs risk assessment tools, can't be performed by workers without risk assessment training and they should be carried out by experts in its application and interpretation.

Facing the distinct scores obtained with the different methods at the same workstation, it seems relevant the proposal (develop) of a previous methods criteria selection.

\section{CONCLUSIONS}

We then concluded that the WRULMSDs risk assessment methods selection must be clear and based on scientific literature and that it can't be made without a workstation rigorous knowledge which determines the eviction of a "universal method" of risk evaluation for this kind of disorders. Most of the time we are measuring risk factors with different criteria and the obtained results do not measure what we think we're measuring.

The use of any tool, checklist, filter or method, should be done by ergonomic risk assessment experts with training in the methods application. This perspective does not entirely agree with the ones that propose a risk assessment model with inexpert workers responsible for risk assessment steps but highlight the need of a gradual risk assessment model at witch workers had a significant contribution. Within this scope, expertise is required for an accurate WRULMSDs risk assessment and management. 


\section{REFERENCES}

1. Balogh I - Questionnaire-based mechanical exposure indices for large population studies: reliability, internal consistency and predictive validity. Scandinavian Journal of Work and Environmental Health 2001; 27 (1): 41-48.

2. Bernard B ed. lit. - Musculoskeletal disorders and workplace factors: a critical review of epidemiologic evidence for work-related musculoskeletal disorders of the neck, upper extremity and low back. Cincinnati: NIOSH; 1997.

3. Buckle P, Devereux J - Work-related neck and upper limb musculoskeletal disorders. Luxembourg: European Agency for Safety and Health at Work; 1999.

4. Fredrikson K - On causes of neck and shoulder pain in the general population. Stockholm: National Institute for Working Life; 2000. Doctoral Thesis.

5. Hakkanen M, Viikari-Juntura E, Takala E Effects of changes in work methods on musculoskeletal load: an intervention study in the trailer assembly. Applied Ergonomics 1997; 28(2): 99-108.

6. KarwowskI W, Marras W - The occupational ergonomics handbook. New York: CRC Press; 1999.

7. NRC (The National Research Council). IOM (Institute of Occupational Medicine) - Musculoskeletal disorders and the workplace: low back and upper extremities : Panel on Musculoskeletal Disorders and the Workplace. Washington, DC: National Academy Press; 2001.

8. Serranheira F, Uva A - Work-related musculoskeletal disorders risk assessment: RULA and SI application. Revista Portuguesa de Saúde Pública 2006; Thematic Issue 13-36.
9. HSE - Upper limb disorders in the workplace. Norwich: Health and Safety Executive; 2002. (HSG60 rev)

10. Occhipinti E - OCRA: a concise index for the assessment of exposure to repetitive movements of the upper limbs. Ergonomics 1998; 41 (9): 12901311.

11. McAtamney L, Corlett E - RULA: rapid upper limb assessment: a survey method for the investigation of work-related upper limb disorders. Applied Ergonomics 1993; 24 (2): 91-99.

12. Moore J, Garg A - The strain index: a proposed method to analyse jobs for risk of distal upper extremity disorders. American Industrial Hygiene Association Journal 1995; 56: 443-458.

13. Lakto W et al. - Development and evaluation of an observational method for assessing repetition in hand tasks. American Industrial Hygiene Association Journal 1997; 58 (4): 278-285.

14. Serranheira F, Lopes F, Uva A - Musculoskeletal disorders and work: a frequent association. Saúde \& Trabalho 2005; 5: 59-88.

15. Serranheira, F. - Contribute to risk assessment of musculoskeletal disorders. Lisbon: National School of Public Health - New University of Lisbon; 1999.

16. Serranheira F - Work-related musculoskeletal disorders: which risk assessment methods? Lisbon: National School of Public Health - New University of Lisbon; 2007. Doctoral thesis.

17. Spielholz P et al. - Baseline exposure assessment results from a prospective study of upper extremity musculoskeletal disorders. Olympia: Washington Department of Labor and Industries; 2004. 